\title{
Estudio del saque en jóvenes jugadores/as de voleibol, considerando la eficacia y función en juego Study of service in young volleyball players, taking into account efficacy and role play
}

\author{
*Alexander Gil Arias, *M. Perla Moreno Arroyo, *Alberto Moreno Domínguez, **Luís García González, \\ *Fernando Del Villar Álvarez \\ *Universidad de Extremadura; **Universidad de Zaragoza
}

\begin{abstract}
Resumen: El objetivo fundamental del presente estudio fue analizar el saque de voleibol en etapas de formación en base a la función en juego del jugador sacador y receptor, así como su eficacia, estableciendo además asociaciones entre las variables mencionadas y el género. Para tal fin, se analizaron un total de 1827 acciones de saque pertenecientes al Campeonato de España de selecciones autonómicas de categoría cadete del año 2005. Los resultados muestran que tanto los chicos como las chicas orientan el balón de saque a otros jugadores que no son ni atacantes-delanteros, ni colocadores, ni líberos. Sin embargo, en la variable eficacia, en los chicos predominan los saques que permiten la construcción de ataques múltiples, mientras que las chicas efectúan saques que limitan las opciones de construcción del ataque. En el análisis inferencial, la variable género se asocia significativamente con las tres variables consideradas en la investigación, donde la realización del saque por parte de los receptores-atacantes y saques con eficacia 1 y 0 se asocian significativamente y de manera positiva con el género masculino, mientras que la realización del saque por parte del opuesto y el central y la eficacia 3 y 4 se asocian significativamente y de manera positiva con el género femenino.
\end{abstract}

Palabra clave: voleibol, saque, eficacia, función en juego, etapa de formación.

\begin{abstract}
The main objective of this study was to analyze the volleyball serve formative stages based on the function punch game player and receiver, and its effectiveness, and also establishing partnerships between these variables and gender. To this end, we analyzed a total of 1827 shares belonging to pull Spain Championship regional selections cadet class of 2005. The results show that both boys and girls guide to serve the ball to other players who are neither attackers-front, or underwriters, or releasing. However, the variable effectiveness, predominate in children serves to permit the construction of multiple attacks, while girls performed serves to limit the options of building the attack. In the inferential analysis, the gender variable is significantly associated with the three variables considered in the investigation, where the completion of the service by receptor-bombers and effectively services 1 and 0 are associated significantly and positively with male gender while carrying out the services from the opposite and the central and efficacy 3 and 4 are associated significantly and positively with the female gender.
\end{abstract}

Key words: volleyball, service, efficacy, game role, formation stage.

\section{Introducción}

El voleibol es un deporte de cooperación-oposición practicado por dos equipos de seis jugadores cada uno y que mediante la utilización de gestos o habilidades abiertas, en un terreno de 18 metros de largo por 9 de ancho y separados por una red, se pretende enviar el balón en las peores condiciones posibles al campo contrario para dificultar su neutralización, consiguiendo de esta manera punto, ya sea por fallo del adversario, o bien por mandar el balón a zonas del campo contrario que imposibiliten su neutralización. Según esto, estamos ante una actividad física de carácter acíclica, con duración indefinida y prolongada, y acciones de máxima aceleración e intensidad (Damas y Julián, 2002).

En el desarrollo de una jugada en voleibol, las acciones finales son las que más determinan el rendimiento de un equipo, pero existen una serie de acciones intermedias, como la recepción y la colocación, que favorecen la secuencia de juego, a través de las que no es posible la consecución de punto de manera directa (Moreno, Moreno, Julián y Del Villar, 2005). Así, la calidad de estas acciones intermedias afecta directamente a la eficacia de las acciones deculminación. De esta manera, la ejecución del ataque dependen en gran medida de la calidad de las acciones anteriores, es decir, el hecho de haber una buena recepción del saque aumenta las posibilidades de realizar una buena colocación, obteniendo así más garantía de éxito en la culminación de la jugada (Papadimitriou, Pashali, Sermaki, Mellas y Papas, 2004). La recepción del saque es un elemento primordial que afecta directamente a la construcción del ataque, y por este motivo el contacto del balón en la recepción está condicionado por la trayectoria y velocidad del saque adversario (Alberda, 1995; Ureña, 1998, Ureña, Santos, Martínez, Calvo

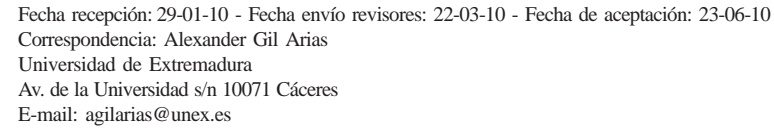

y Oña, 2000), por lo que sin una buena técnica de recepción estamos facilitando la labor defensiva del contrario (Fröhner, 1988; Toyoda y Herrera, 1989; Ureña y Iglesias, 1993), y por este motivo el trabajo del saque y de la recepción en el proceso de entrenamiento resulta ser una tarea primordial para la mayoría de los equipos (Ureña, et al., 2001), ya que tal y como indican Asterios, Kostantinos, Athanasios y Dimitrios, (2009) el ataque que procede de la recepción del servicio constituye el mejor predictor para ganar un punto directamente después del servicio del oponente.

Son muchos los autores que coinciden en indicar que el saque es la primera opción de puntuar para un equipo (Ejem, 2001; Díaz, 2001). Monge (2001) propone que dentro de una jugada existen tres objetivos: controlar, construir y culminar, situando la acción de saque dentro de las acciones de culminación con la posibilidad de conseguir punto.

La estructura del voleibol se divide principalmente en dos complejos de juego: complejo I y complejo II, en donde el primero es conocido como el complejo de ataque, mientras que el segundo es identificado como el complejo de defensa. Posteriormente, autores como Herrera, Ramos, Despaigne (1996) introducen un tercer complejo definido como la fase de juego que se deriva de la finalización del KI y KII o lo que también es denominado como juego medio. Monge (2001, 2002) propone añadir dos complejos más para definir completamente las secuencias de juego, por lo que se introduce el complejo 0 y el complejo 4, donde el complejo 0 hace referencia a todas las secuencias que realiza un equipo con el saque a favor, como inicio de toda jugada estando compuesto tan solo por la acción de saque, justificando de esta manera la importancia del saque en el juego.

En los inicios del voleibol, al saque se le consideraba como una puesta en juego del balón, pero con el paso del tiempo ha pasado a considerarse una acción técnico-táctica ofensiva (Maia y Mesquita, 2006), llegando a desarrollarse como un arma de ataque (Díaz-García, 2000), a través de la cual un equipo puede obtener punto de manera directa (Ejem, 2001). En la actualidad, el jugador al saque cuando se dispone a efectuar el servicio es necesario que tenga una determinada 
intención táctica, ya que al equipo contrario no se le puede dar la oportunidad de construir el ataque (Molina, 2003).

A lo largo de la historia del voleibol se han producido numerosos cambios reglamentarios y, de acuerdo con el objetivo del estudio, queremos destacar los siguientes:

- Incorporación del jugador líbero, por lo que cada equipo tiene la opción de registrar al final de la lista de 12 jugadores, un jugador especializado en defensa que ayudará a aumentar el rendimiento en la recepción y por tanto, mejorar el KI facilitando así la obtención de punto. En la investigación llevada a cabo por Ureña, Calvo y Lozano (2002) llegaron a concluir que la participación del líbero en la recepción del saque no suponeninguna variación significativa del rendimiento de esta acción, ni en el resultado de la jugada en general. Sin embargo, Jõao, Mesquita, Sampaio y Mouthino (2008) constataron que cuando el jugador líbero intervenía en recepción se obtenía una mayor eficacia, proporcionando mejores condiciones en la distribución del ataque que cuando intervenían los jugadores principales en recepción. De esta manera, Zimmermann (1999) y Murphy (1999) concluyeron que esta figura está teniendo más repercusión sobre la recepción del saque que sobre la defensa, por lo que se ve favorecido el juego de ataque disminuyendo las opciones de puntuar del equipo que defiende.

- Cambio del sistema de puntuación del «cambio de saque» a «fase punto total» o «Rally Point System», por lo que en voleibol, cada jugada vale punto. Este cambio ha supuesto la implantación de dos filosofías de juego en cuanto al saque: por un lado aquella que prefiere darle todo el protagonismo al servicio, es decir, sacar a puntuar, ya sea a favor o en contra. Y por otro lado, aquella que prefiere darle un riesgo controlado al saque, y por consiguiente dotar al KII de un mayor protagonismo (Blain, 2001 citado por Molina, 2003).

Como consecuencia de estos cambios reglamentarios, que afectan directa o indirectamente al saque, se han desarrollado diversos trabajos de investigación centrados en el análisis del saque en alto rendimiento y en etapas de formación. En voleibol masculino de alto nivel cabe destacar el estudio de Moreno, Molina y Santos (2008) que analizaron con profundidad las características del saque considerando entre otras, las variables de eficacia del saque, función en juego del jugador al saque, corriente del marcador y clasificación del equipo.

Por otro lado, Ureña, Calvo y Gallardo (2000) establecieron las variables que afectan al rendimiento de la recepción del saque, principalmente en relación con el saque del oponente y la participación del líbero. Centrándose en esta figura especialista en defensa, Callejón (2006a) realizó un estudio cuantitativo de las intervenciones con balón del jugador líbero en partidos de máximo nivel competitivo, analizando en términos generales la participación de esta figura en diferentes situaciones tales como la recepción y la defensa del ataque. En esta misma línea, Callejón y Hernández (2009) con el objetivo de determinar las tendencias en la recepción en el voleibol masculino de alto rendimiento, analizaron las recepciones de los saques tanto de los jugadores del Equipo Nacional Masculino, como también las realizadas por los equipos adversarios. Con esta misma muestra, Callejón (2006b) determinó cuáles son las tendencias del saque en el Voleibol masculino de alto rendimiento, considerando diferentes variables relativas al saque, como son la eficacia, el tipo de técnica utilizada, así como las zonas de origen e impacto.

En etapas de aprendizaje, González (2003) con una muestra de infantil masculino estudió como afecta la técnica de saque sobre el rendimiento del complejo I, sobre el número de construcciones del complejo II, sobre la culminación del punto, sobre el número de contactos con el balón realizados por equipo, sobre el número de transiciones del balón al campo contrario logradas por el equipo, sobre el índice de continuidad de las acciones de juego y sobre el resultado del punto.

Debido a la introducción del nuevo sistema de puntuación, diversos autores se han mostrado críticos (Thines, 1992), ya que la introducción del tanteo acción-punto supondría a los equipos asumir un menor riesgo en el saque. En relación a este planteamiento, en alto rendimiento, Marcelino, Mesquita y Afonso (2008) confirmaron que los mejores equipos presentaban un alto número de errores en el saque, explicando estos valores por la necesidad de incrementar el riesgo en el saque con el objetivo de neutralizar la eficacia del ataque del oponente, confirmando de esta manera una tendencia contraria en la concepción del nuevo sistema de puntuación (Zimmermann, 1995; Ejem, 2001). En lo que se refiere a categorías de formación, García- Tormo, Redondo, Valladares y Morante (2006) analizaron el nivel de riesgo que asumen las jugadoras de voleibol en el servicio y la eficacia que obtienen con los mismos, relacionando estos resultados con otras variables tales como la dirección del saque, tipo de saque, diferencia de puntos en el marcador y los puntos restantes para el final del set.

El objetivo fundamental del presente estudio fue analizar el saque de voleibol en etapas de formación en base a la función en juego del jugador sacador y receptor, así como su eficacia, estableciendo además asociaciones entre las variables mencionadas y el género.

\section{Método}

\subsection{Muestra}

La muestra del estudio estuvo compuesta por los saques realizados por los equipos participantes en el Campeonato de España de selecciones autonómicas de categoría cadete del año 2005. Se analizaron 1827 acciones de saques, delos cuales 886 pertenecen al género masculino y 941 al género femenino, realizadas en un total de 88 sets en 11 partidos.

\subsection{Variables}

Las variables consideradas en el estudio fueron las siguientes: rol del receptor, rol del sacador, eficacia del saque y género.

Indicamos a continuación el grado de apertura de cada una de las variables.

Rol del receptor: Definido como el rol o función en juego del jugador al que es dirigido el saque para su recepción. Se diferencian cuatro funciones de juego:

-Colocador: El saque es dirigido y recibido por el colocador o jugador que cubre a éste.

-Atacante-Delantero: El saque es dirigido y recibido por el atacante delantero.

-Líbero: El saque es dirigido y recibido por el jugador líbero.

-Otros: El saque es dirigido y recibido por jugadores con funciones de juego diferentes a las mencionadas anteriormente.

Rol del sacador: Definido como el rol o función en juego del jugador que efectúa el saque. Se diferencian cuatro roles de juego:

-Colocador: El saque es realizado por un colocador.

-Receptor-atacante: El saque es realizado por un receptor-atacante. -Central: El saque es realizado por un central.

-Opuesto: El saque es realizado por un opuesto.

Eficacia del saque: Definido como el rendimiento o efecto obtenido con el saque. Para la valoración de la eficacia se ha empleado el sistema estadístico FIVB, adaptado de Coleman (1975), diferenciando los siguientes valores:

-0 : Error de saque.

-1 : Saque que permite la construcción de cualquier tipo de ataque.

-2 : Saque que limita las opciones de construcción del ataque, no permitiendo la realización de ataques rápidos.

-3 : Saque que imposibilita la construcción del ataque y supone el envío de un free ball.

-4: Punto directo.

Género: masculino y femenino.

\subsection{Medida e instrumentos}

Mediante la observación sistemática del saque se realizó la medida de las variables indicadas anteriormente.

Para la grabación de los partidos disputados se empleó una cámara digital JVC GR-DVP9 que fue colocada en uno de los fondos del campo en el cual se disputaban los partidos a una altura de 6 metros. Todo ello permitió la visualización del saque en ambos equipos, permitiendo 
además que durante la reproducción se apreciase la totalidad del campo con la mayor claridad posible.

Las grabaciones realizadas con la videocámara se hacían sobre formato MINI-DV que nos permitía reproducirlo en un reproductor MINI-DV, al objeto de hacer la observación del estudio y entrenamiento de observadores. Para estos procesos se utilizó un reproductor de marca SONY y modelo DSR-30P y un televisor de marca Panasonic y modelo 28N33D.

Una vez realizada la recogida de datos se procedió a la observación de todos y cada uno de los partidos por un único observador. Para ello fue necesario pasar un proceso de entrenamiento de observadores con el fin de alcanzar una fiabilidad superior al 80\% que nos garantizase la consistencia en la medida (Van Der Mars, 1989). El entrenamiento se llevó a cabo en un total de 2 sesiones, llegándose a alcanzar valores de fiabilidad del $100 \%$ en la variable rol del receptor, $100 \%$ en rol del sacador y $91.43 \%$ en la eficacia del saque.

\section{Resultados}

A continuación se presenta el análisis descriptivo de cada variable, así como el análisis inferencial, basándonos en las tablas de contingencia, los valores de Chi-cuadrado y V de Cramer, para conocer las posibles relaciones existentes entre las diferentes variables consideradas en el estudioy el género de los/as jugadores/as al saque. Elnivel de significación estadística considerado fue de $\mathrm{p}<0.05$.

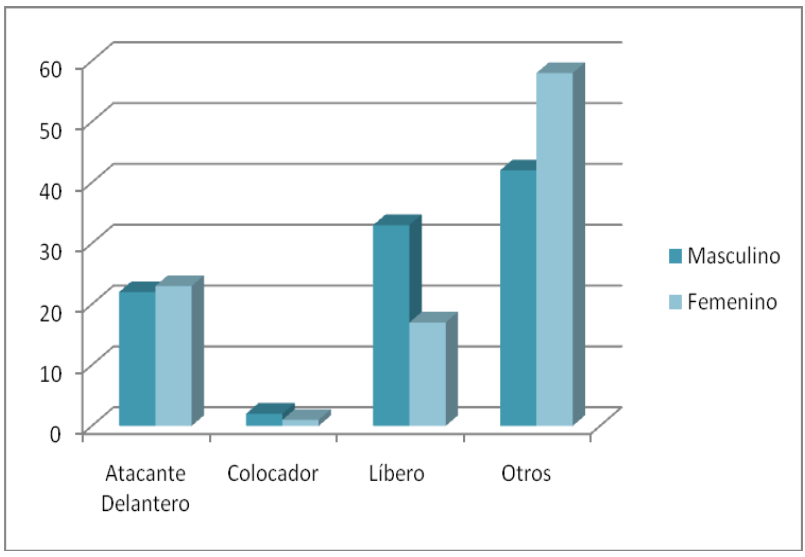

Figura 1: Porcentaje de saques en función del rol del receptor en masculino y femenino

\section{- Rol del receptor-género}

Atendiendo a la distribución de frecuencias, tal y como se muestra en la Figura 1, los chicos envían, con un valor del $42.5 \%$, los saques a otros jugadores que no son ni atacantes-delanteros, ni colocadores, ni liberos, siendo el número de saques enviados a los colocadores muy reducido (2.4\%). En el caso de las chicas, al igual que en los chicos, la mayoría de los saques fueron enviados al grupo de otros, seguido de los balones enviados al grupo de atacantes-delanteros y libero, con

\begin{tabular}{|c|c|c|c|c|c|}
\hline \multicolumn{6}{|c|}{ TABLA 1. Tabla de contingencia Función del Receptor - género } \\
\hline & & & Gér & & Total \\
\hline & & & Masculino & Femenino & \\
\hline \multirow{16}{*}{$\begin{array}{l}\text { Función del } \\
\text { Receptor }\end{array}$} & \multirow{4}{*}{$\begin{array}{l}\text { Atacante } \\
\text { Delantero }\end{array}$} & Recuento & 165 & 187 & 352 \\
\hline & & Frecuencia esperada & 169.4 & 182.6 & 352.0 \\
\hline & & \begin{tabular}{|l|}
$\%$ de Género \\
\end{tabular} & $22.2 \%$ & $23.4 \%$ & $22.8 \%$ \\
\hline & & Residuos corregidos & -.5 & .5 & \\
\hline & \multirow{4}{*}{ Colocador } & Recuento & 18 & 10 & 28 \\
\hline & & Frecuencia esperada & 13.5 & 14.5 & 28.0 \\
\hline & & \% de Género & $2.4 \%$ & $1.3 \%$ & $1.8 \%$ \\
\hline & & Residuos corregidos & 1.7 & -1.7 & \\
\hline & \multirow{4}{*}{ Líbero } & Recuento & 244 & 135 & 379 \\
\hline & & \begin{tabular}{|l} 
Frecuencia esperada \\
\end{tabular} & 182.4 & 196.6 & 379.0 \\
\hline & & \% de Género & $32.9 \%$ & $16.9 \%$ & $24.6 \%$ \\
\hline & & Residuos corregidos & 7.3 & -7.3 & \\
\hline & \multirow{4}{*}{ Otros } & Recuento & 315 & 468 & 783 \\
\hline & & Frecuencia esperada & 376.8 & 406.2 & 783.0 \\
\hline & & \% de Género & $42.5 \%$ & $58.5 \%$ & $50.8 \%$ \\
\hline & & \begin{tabular}{|l} 
Residuos corregidos \\
\end{tabular} & -6.3 & 6.3 & \\
\hline \multirow{3}{*}{\multicolumn{2}{|c|}{ Total }} & Recuento & 742 & 800 & 1542 \\
\hline & & \begin{tabular}{|l|} 
Frecuencia esperada \\
\end{tabular} & 742 & 800 & 1542 \\
\hline & & \% de Género & $100 \%$ & $100 \%$ & $100 \%$ \\
\hline
\end{tabular}

porcentajes de $23.4 \%$ y $16.9 \%$ respectivamente, destacando en este grupo el reducido valor porcentual de saques orientados hacia el colocador.

En el análisis inferencial, la Tabla 1 nos da a conocer la asociación significativa entre las variables función del receptor y género $\left(x^{2}=62.813\right.$; $\mathrm{V}$ de Cramer $=.202 \mathrm{p}=.000$ ). Las celdas que contribuyen de manera positiva a esta asociación son: líbero con género masculino y otros con género femenino, asociándose negativamente estas mismas casillas con el género contrario.

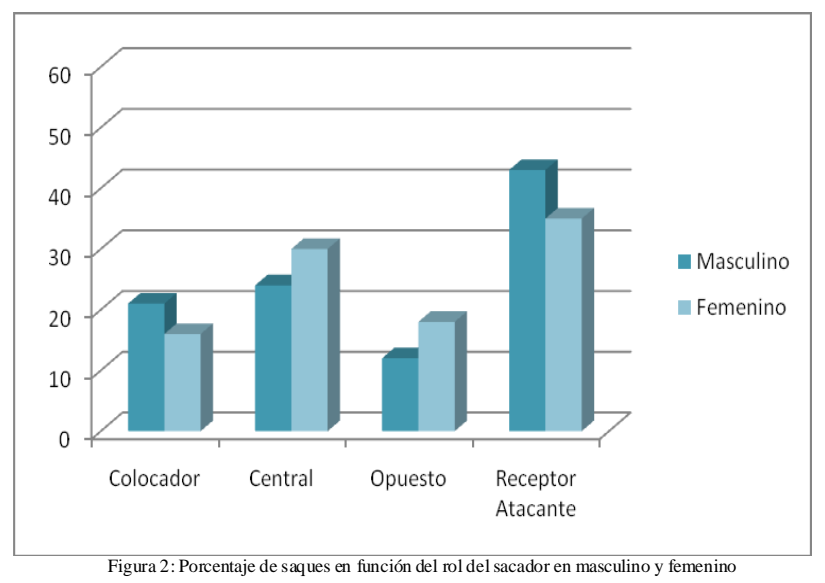

- Rol del sacador-género

En lo que se refiere a la variable rol del sacador y más concretamente en el género masculino, la Figura 2 nos muestra que el $42.9 \%$ de los saques son efectuados por los receptores-atacantes, seguido de los centrales, colocadores y opuestos que obtuvieron respectivamente unos porcentajes de $24.0 \%, 21.2 \%$ y $11.9 \%$. En el caso del género femenino, el 35.5\% de los servicios son llevados a cabo por el grupo de receptoresatacantes, seguido de los centrales con un porcentaje de 30.1\%, destacando los valores tan similares que han obtenido el grupo de colocadores y opuestos (16.3\% para el grupo de colocadores y $18.1 \%$ para el grupo de opuestos).

\begin{tabular}{|c|c|c|c|c|c|}
\hline \multicolumn{6}{|c|}{ TABLA 2. Tabla de contingencia Rol del Sacador - género } \\
\hline & & & \multicolumn{2}{|c|}{ Género } & \multirow{2}{*}{ Total } \\
\hline & & & Masculino & Femenino & \\
\hline \multirow{16}{*}{ Rol del Sacador } & \multirow{4}{*}{ Colocador } & Recuento & 187 & 153 & 340 \\
\hline & & Frecuencia esperada & 164.8 & 175.2 & 340.0 \\
\hline & & \% de Género & $21.2 \%$ & $16.3 \%$ & $18.7 \%$ \\
\hline & & Residuos corregidos & 2.7 & -2.7 & \\
\hline & \multirow{4}{*}{ Central } & Recuento & 212 & 283 & 495 \\
\hline & & Frecuencia esperada & 239.9 & 255.1 & 495.0 \\
\hline & & \% de Género & $24.0 \%$ & $30.1 \%$ & $27.2 \%$ \\
\hline & & Residuos corregidos & -2.9 & 2.9 & \\
\hline & \multirow{4}{*}{ Opuesto } & Recuento & 105 & 170 & 275 \\
\hline & & Frecuencia esperada & 133.3 & 141.7 & 275.0 \\
\hline & & \% de Género & $11.9 \%$ & $18.1 \%$ & $15.1 \%$ \\
\hline & & Residuos corregidos & -3.7 & 3.7 & \\
\hline & \multirow{4}{*}{ Receptor atacante } & Recuento & 379 & 333 & 712 \\
\hline & & Frecuencia esperada & 345.1 & 366.9 & 712.0 \\
\hline & & \% de Género & $42.9 \%$ & $35.5 \%$ & $39.1 \%$ \\
\hline & & Residuos corregidos & 3.3 & -3.3 & \\
\hline \multirow{3}{*}{\multicolumn{2}{|c|}{ Total }} & Recuento & 883 & 939 & 1822 \\
\hline & & Frecuencia esperada & 883 & 939 & 1822 \\
\hline & & \% de Género & $100 \%$ & $100 \%$ & $100 \%$ \\
\hline
\end{tabular}

La Tabla 2 muestra los valores de la relación entre las variables rol del sacador y género, llegando a ser una asociación significativa $\left(x^{2}=16.649\right.$; $\mathrm{V}$ de Cramer $\left.=.129 \mathrm{p}=.000\right)$. Las casillas que contribuyen a esta asociación de manera positiva son: opuesto con género femenino, receptor-atacante con género masculino, central con género femenino y colocador con género masculino, destacando que estas mismas celdas se asocian negativamente con el género opuesto.

- Eficacia del saque-género

Como puede apreciarse en la Figura 3, en el género masculino el porcentaje más elevado de saques (35.7\%) correspondió a servicios con eficacia 1 , es decir, saques que posibilitan la construcción de cualquier tipo de ataque. El porcentaje de error en el saque (saques con eficacia 0) y saques que imposibilitan la construcción del ataque y supone el envío de un free ball (saques con eficacia 3), obtuvieron respectivamente unos 


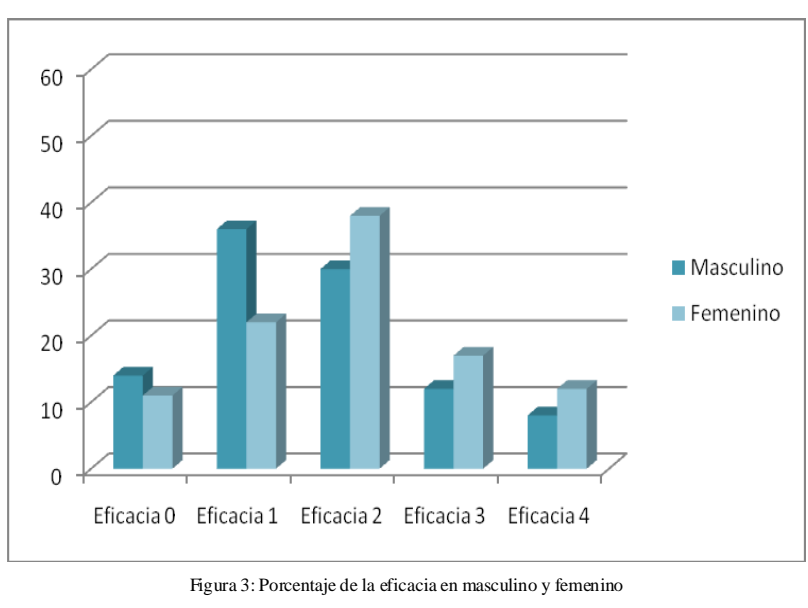

porcentajes de $13.9 \%$ y $12.3 \%$. Atendiendo al género femenino, el porcentaje más elevado de saques (37.7\%) correspondió a servicios con eficacia 2, o lo que es lo mismo, saques que limitan las opciones de construcción del ataque, no permitiendo la realización de ataques rápidos. La obtención de error en el saque (saques con puntuación 0) y saques que supone la obtención de punto de directo, obtuvieron unos porcentajes de $10.7 \%$ y $12.5 \%$ respectivamente. La relación entre saques fallados y puntos directos logrados con el saque, está cercana a 2:1 en el género masculino y 1:1 en el femenino, es decir, en el caso de los chicos, aproximadamente se fallan dos saques por cada uno mediante el cual se obtiene punto directo, mientras que en el caso de las chicas se falla un saque por cada uno a través del cual se obtiene punto directo.

En el análisis inferencial, existe una asociación significativa entre la eficacia del saque y el género ( $x^{2}=59.463$; $V$ de Cramer=.181; $p=.000$ ). Las celdas que contribuyen de forma positiva a esta asociación son: ataque combinado con género masculino, ataque sin primeros tiempos con género femenino, punto directo con género femenino y error en saque con género masculino; destacando que estas mismas celdas se asocian negativamente con el género opuesto.

\begin{tabular}{|c|c|c|c|c|c|}
\hline \multicolumn{6}{|c|}{ TABLA 3 Tabla de contingencia eficacia - género } \\
\hline & & & \multicolumn{2}{|c|}{ Género } & \multirow{2}{*}{ Total } \\
\hline & & & Masculino & Femenino & \\
\hline \multirow{20}{*}{ Eficacia } & \multirow{4}{*}{ Eficacia 0 (Error en saque) } & Recuento & 123 & 101 & 224 \\
\hline & & Frecuencia esperada & 108.5 & 115.5 & 224 \\
\hline & & \%de Género & $13.9 \%$ & $10.7 \%$ & $12.3 \%$ \\
\hline & & \begin{tabular}{|l} 
Residuos corregidos \\
\end{tabular} & 2.1 & -2.1 & \\
\hline & \multirow{4}{*}{$\begin{array}{l}\text { Eficacia } 1 \text { (Ataque } \\
\text { combinado) }\end{array}$} & Recuento & 316 & 205 & 521 \\
\hline & & Frecuencia esperada & 252.4 & 268.6 & 521 \\
\hline & & \%de Género & $35.7 \%$ & $21.8 \%$ & $28.5 \%$ \\
\hline & & \begin{tabular}{|l|} 
Residuos corregidos \\
\end{tabular} & 6.6 & -6.6 & \\
\hline & \multirow{4}{*}{$\begin{array}{l}\text { Eficacia2 (Ataque sin } \\
\text { primeros tiempos) }\end{array}$} & Recuento & 266 & 355 & 621 \\
\hline & & Frecuencia esperada & 300.8 & 320.2 & 621 \\
\hline & & \%de Género & $30.1 \%$ & $37.7 \%$ & $34.0 \%$ \\
\hline & & Residuos corregidos & -3.4 & 3.4 & \\
\hline & \multirow{4}{*}{ Eficacia 3 (Envía Freeball) } & Recuento & 109 & 162 & 271 \\
\hline & & Frecuencia esperada & 131.3 & 139.7 & 271 \\
\hline & & \%de Género & $12.3 \%$ & $17.2 \%$ & $14.8 \%$ \\
\hline & & Residuos corregidos & -2.9 & 2.9 & \\
\hline & \multirow{4}{*}{ Eficacia 4 (Punto directo) } & Recuento & 70 & 118 & 188 \\
\hline & & \begin{tabular}{|l} 
Frecuencia esperada \\
\end{tabular} & 91.1 & 96.9 & 188.0 \\
\hline & & \% de Género & $7.9 \%$ & $12.5 \%$ & $10.3 \%$ \\
\hline & & \begin{tabular}{|l} 
Residuos corregidos \\
\end{tabular} & -3.2 & 3.2 & \\
\hline \multirow{3}{*}{\multicolumn{2}{|c|}{ Total }} & \begin{tabular}{|l} 
Recuento \\
\end{tabular} & 884 & 941 & 1825 \\
\hline & & Frecuencia esperada & 884 & 941 & 1825 \\
\hline & & \% de Género & $100 \%$ & $100 \%$ & $100 \%$ \\
\hline
\end{tabular}

\section{Discusión}

El objetivo fundamental del presente estudio fue analizar el saque de voleibol en etapas de formación en base a la función en juego del jugador sacador y receptor, así como su eficacia, estableciendo además asociaciones entre las variables mencionadas y el género.

Haciendo referencia a la función del receptor, la presente investigación nos muestra que los chicos envían en mayor medida los servicios a otros jugadores que no son ni libero, ni atacantes delanteros, ni colocadores, subrayando la escasa frecuencia de saques que son orientados a los colocadores. Estos resultados van en consonancia con los obtenidos por Ureña, et al. (2002) con una muestra de la División de Honor masculina, en donde la participación de los receptores-zagueros en recepción es superior a la del líbero y receptor-delantero, concluyendo los autores que la participación del líbero en la recepción del saque no supone ninguna variación significativa del rendimiento de esta acción ni en el resultado de la jugada en general.

En esta misma línea, Callejón (2006a) con jugadores líberos tanto del equipo Nacional masculino como de los equipos adversarios de las Competiciones de la Liga Mundial de Voleibol de 2003, obtuvo resultados muy similares a los obtenidos en el presente estudio en lo que se refiere a la participación del líbero en recepción. Sin embargo, en esta misma investigación, el 63.6\% de las recepciones corrían a cargo de los otros dos receptores, mientras que en nuestro estudio el $42.5 \%$ de las recepciones corrían a cargo de otros jugadores que no son ni libero, ni colocadores, ni atacantes-delanteros.

Por otro lado, Molina (2003, 2007) con jugadores de Primera División Nacional Masculina obtuvo también resultados semejantes a los obtenidos en nuestra investigación, en donde el jugador que más veces recibió el saque fue el jugador zaguero independientemente del tipo de saque.

Sin embargo, Joao, Mesquita, Moutinho y Mota (2005) en un estudio realizado sobre la Liga Mundial de Voleibol, en el año 2001, mostraron que la aportación del líbero al equipo en la recepción del saque suponeun $57.1 \%$, mientras que el resto de los receptores intervienen en un $42.9 \%$, resultados que difieren de los obtenidos en el presente estudio.

Por último, Ureña, Calvo y Gallardo (2000) con una muestra que estaba conformada por el Equipo Nacional masculino que participó en el Campeonato del Mundo de 1998, considerando también la función del receptor, comprobó que más de la mitad de los servicios fueron orientados hacia jugadores zagueros, seguido de los saques que fueron neutralizados por los jugadores delanteros y líberos con porcentajes de $24.7 \%$ y $20.7 \%$ respectivamente. Estos resultados difieren a los obtenidos por nosotros, donde el libero intervino en recepción en un $32.9 \%$ de las ocasiones, destacando el valor tan similar en lo que se refiere a los jugadores delanteros.

Haciendo un análisis comparativo de los estudios mencionados anteriormente, se confirma el significado aumento de la participación del líbero en la recepción de los saques (36.4\% en la Liga Mundial de 2003 frente al 20.7\% de los Campeonatos del Mundo de 1998), destacando que el año 1998 fue el primer año de implantación del jugador líbero en competición oficial.

El hecho de que los jugadores atacantes-delanteros reciban en el presente estudio en un $20 \%$ menos de las ocasiones respecto a aquellos jugadores que no son ni atacantes delanteros, ni colocadores y ni liberos puede estar relacionado con el hecho de que con la incorporación del líbero se incrementa las posibilidades de eliminar a los jugadores más ofensivos del sistema de recepción.

Atendiendo al género femenino, los resultados descriptivos nos dan a conocer que más de la mitad de las recepciones de los saques corrían a cargo del grupo otros, seguido del grupo de atacantes-delanteras, libero y colocadoras. En este mismo género, pero con una muestra procedente de la División de Honor Femenina destacamos el estudio de Lozano (2007), en el cual se consideró la variable función de la receptora, llegando a resultados que no difieren mucho de los obtenidos en nuestro estudio. En el estudio mencionado se halló que el 25.1\% de la recepción de los saques eran llevados a cabo por las jugadoras líberos, mientras que el $50.9 \%$ corrían a cargo de las jugadoras zagueras-receptoras. Con estos resultados se demuestra la relevante presencia de la líbero en la acción de recepción como ya se ha demostrado en estudios anteriores (Murphy, 1999; Peña, 2000).

Resulta importante destacar que tanto en etapas de formación como en el voleibol de alto rendimiento es muy reducido el porcentaje de saques que son enviados a jugadores que se encuentran fuera del sistema de recepción como pudiera ser el caso del colocador. Esto nos da a entender que los sacadores, en etapas de formación, como es el caso de nuestro estudio, no son lo suficientemente consciente de la ventaja que se obtiene al orientar el balón de saque a este tipo de jugadores con la finalidad de reducir su participación en la fase de construcción del ataque, facilitando asíla labor defensiva del equipo sacador. Otra explicación a 
todo esto, podría ser la estabilidad en la técnica de saque, ya que al encontrarnos con jugadores en etapas de formación es posible que el patrón técnico del saque no lo tengan lo suficientemente estabilizado como para enviar el balón con precisión a un jugador o una zona determinada.

En lo que se refiere a la asociación de la variable rol del receptor en función del género existe una asociación significativa siendo más frecuente que lo esperado por el azar el envío del balón al libero con género masculino y otros con género femenino.

Atendiendo a la variable rol del sacador, la mayor parte de los saques masculinos fueron efectuados por los receptores-atacantes, seguido de los centrales y colocadores, matizando el reducido valor de saques efectuados por los jugadores opuestos. Estos resultados coinciden con los obtenidos por Moreno et al. (2008), donde los centrales y atacantes-receptores efectuaron la mayoría de los saques, realizando los opuestos un menor porcentaje de saques que los colocadores. En lo que se refiere al género femenino, se encuentran resultados similares entre los saques realizados por las receptoras-atacantes y centrales al igual que ocurre entre las opuestas y colocadoras. Estos resultados coinciden en parte con los obtenidos en el estudio de Quiroga et al. (en prensa), en el cual se manifestaron valores porcentuales similares entre las centrales y receptoras-atacantes al igual que entre las colocadoras y opuestas.

Haciendo mención al análisis inferencial se comprueba que existe una asociación significativa entre rol del sacador y género, siendo más frecuente que lo esperado por el azar el rol de colocador y receptoratacante con género masculino y el rol de central y opuesto con género femenino.

La eficacia del saque que más frecuentemente se ha obtenido en el género masculino han sido aquellos saques que permiten la construcción de ataques combinados (eficacia 1), seguido de los saques queno permiten la construcción de ataques a primeros tiempos (eficacia 2), siendo el valor porcentual de saques a través de los cuales se obtiene punto directo (eficacia 4) muy reducido. En esta misma línea, Molina (2003) en su estudio con jugadores de nivel intermedio pertenecientes a la Primera División Nacional obtuvo resultados similares, donde la mayor parte de los servicios obtuvieron una eficacia 1 , seguido de los saques con eficacia 2. Sin embargo, Moreno et al. (2008) con una muestra de jugadores de voleibol masculino de alto nivel comprobaron que los saques con eficacia 2 fueron los más frecuentes.

Esta diferencia de resultados puede deberse al nivel de pericia de los jugadores, ya que tanto en nuestro estudio como en el de Molina (2003), con jugadores de nivel bajo y medio, respectivamente, éstos tienden a efectuar saques más controlados que los jugadores de alto nivel, viéndose facilitada así la recepción y aumentándose las posibilidades de construir ataques múltiples. Sin embargo, los jugadores de alto rendimiento tenderán a proporcionar más potencia al saque, por lo que se verá mermada la recepción y como consecuencia de ello se verán limitadas las opciones de ataque.

En el caso del género femenino, los saques con eficacia 2 fueron los que más predominaron frente a los servicios con eficacia 1 y 3 , siendo los valores de los saques con eficacia 4 y 0 ligeramente reducidos. En este mismo género, destacamos el estudio de Lozano (2007) que con una muestra de jugadoras de División de Honor analizó el rendimiento en recepción, no obteniendo resultados muy coincidentes con los hallados en nuestro estudio, ya que la mitad de las recepciones permitían realizar un ataque combinado, seguido de las recepciones que permitían realizar un ataque simple, siendo reducido el valor de las recepciones sin ataque posterior y error de saque.

En referencia a los resultados inferenciales, en la variable eficacia del saque en función del género existe una asociación significativa siendo más frecuente que lo esperado por el azar la realización de saques que permiten ataques combinados y el error en saque con género masculino y la realización de saques que permiten ataques sin primeros tiempos, envío de freeball y punto directo con género femenino. En este sentido, Palao, Santos y Ureña (2004) con una muestra de jugadores de Juegos Olímpicos de Sydney observaron que tanto en categoría masculina como en femenina, la utilización del servicio en salto potente implica un número significativamente mayor de puntos y de errores, que con la utilización del resto de tipos de saques. Este elevado número de errores con este tipo de servicio provoca que dos de cada diez acciones se pierdan directamente por el jugador al saque. Por otro lado, Palao, Manzanares y Ortega (2009) con una muestra de jugadores/as de alto nivel comprobaron que las chicas fueron más efectivas que los chicos en el saque, independientemente de la técnica de saque utilizada. Para las chicas, el saque en salto flotante fue el más efectivo, mientras que para los chicos fue el saque en salto potente.

Atendiendo a la relación que existe entre error-acierto, los chicos mantienen una relación aproximada de 2:1, es decir, se fallan dos saques por cada uno mediante el cual se obtiene punto directo, siendo esta relación relativamente baja respecto a la encontrada por Moreno et al. (2008), que con una muestra de jugadores de Superliga masculina obtuvieron una elevada relación error-acierto en el saque, siendo ésta cercana a 4:1. Sin embargo, las chicas obtuvieron una relación de erroracierto más ajustada, siendo ésta de 1:1, coincidiendo estos resultados con los obtenidos a partir del estudio de García Tormo et al. (2006) con una muestra de jugadoras de categoría juvenil. A partir de estos datos, sería interesante que el equipo técnico calcularan esta relación de manera individual, con el fin de que el entrenador considere la misma para tomar sus decisiones durante la dirección de equipo (Drikos, Kountouris, Laios y Laios, 2009).

\section{Bibliografía}

Alberda, A. (1995). Mayor variedad y versatilidad, perspectivas ofrecidas por la nueva regla del saque, Intemational Volley Teach (edición en castellano), 4/95: 4-7.

Asterios, P., Kostantinos, C., Athanasios, M. y Dimitrios, K. (2009). Comparison of technical skills effectiveness of men's National Volleyball teams. International Journal of Performance Analysis of Sport, 9, 1-7.

Callejón, D. (2006a). Estudio y análisis de la participación técnicotáctica del jugador líbero en el voleibol masculino de alto rendimiento. Tesis Doctoral del Departamento de Física e Instalaciones aplicadas a la Edificación, al Medio Ambiente y al Urbanismo. Universidad Politécnica de Madrid.

Callejón, D. (2006b). Estudio y análisis del saque en el voleibol masculino de alto rendimiento. International Journal of Sport Science, 5, 12 28.

Coleman, J.E. (1975). A statistical evaluation of selected volleyball techniques at the 1974 World's Volleyball Championships. Thesis Physical Education. Brigham Young University.

Damas, J. S. y Julián, J. A. (2002). La enseñanza del voleibol en las escuelas deportivas de iniciación. Madrid. Gymnos.

Drikos, S., Kountouris, P., Laios, A. y Laios, Y. (2009). Correlates of Team Performance in Volleyball. International Journal of Performance Analysis of Sport, 9, 149-156.

Díaz-García, J. (2000). Voleibol español: reflexión, acción. Cádiz. Federación Andaluza de Voleibol (FAVb).

Díaz, J. J. (2001). Evolución de los sistemas de entrenamiento en el cambio de saque desde la perspectiva cubana. VIII Congreso Internacional sobre entrenamiento en voleibol. Importancia de la preparación táctica en la mejora del rendimiento en voleibol. León.

Ejem, M. (2001). Brief technical evaluation of the $27^{\text {th }}$ Olimpiad in Sydney. The Coach 1: 6-12.

Fröhner, B. (1988). Voleibol. Juegos para el entrenamiento. Buenos aires. Stadium.

García-Tormo, J. V.; Redondo J. C.; Valladares, J. A. y Morante, J. C. Análisis del saque de voleibol categoría juvenil femenina en función nivel de riesgo asumido y su eficacia. European Journal of Human Movement. Motricidad, 16, 99-121.

Herrera, G, Ramos, J. y Despaigne, J. (1996). Voleibol: Manual de consulta operativa para el entrenador. Federación Vasca de Voleibol. 
João, P. V.; Mesquita, I.; Mouthinho, C. y Mota, P. (2005). «Study of the pass quality-association with followed attack's conditions and effect of the solution (quality of attack), whenever it is realzed by «libero» player or priotity receivers players». $10^{\circ}$ Congress European College of Sport Science. Belgrado. Julio 2005.

João, P. V.; Mesquita, I.; Sampaio, J. y Mouthinho, C. (2008). Análise comparativa entre o jogador libero e os recebedores prioritários na organização ofensiva, a partir da recepção ao serviço, em voleibol. Revista Portuguesa Ciencias Desporto, 6(3), 318-328.

Lozano, C. (2007). Incidencia del saque y los elementos de la fase de juego del KI sobre el rendimiento de la misma en el voleibol femenino español de alto nivel. Tesis Doctoral del departamento de Educación Física y Deportiva. Universidad de Granada.

Maia, N. y Mesquita, I. (2006). Characterizacion of the serve in the female Volleyball in high competitive outcome. World Congress of Performance Analysis of Sport VII. Szombathely: International Society of Performance Analysis of Sport.

Marcelino, R., Mesquita, I. y Afonso, J. (2008). The weight of terminal actions in Volleyball. Contributions of the spike, serve and block for the teams' rankings in the World League 2005. International Journal of Performance Analysis in Sport, 8, 2, 1-7.

Molina, J.J. (2003). Estudio del saque de voleibol primera división masculina: análisis de sus dimensiones contextual conductual y evaluativa. Tesis Doctoral del Departamento de Educación Física y Deportiva. Universidad de Granada.

Molina, J. J. (2007). Metodología científica aplicada a la observación del saque en voleibol masculino de alto rendimiento. Ed. Wanceulen. Sevilla.

Monge, M. A. (2001). Propuesta de un proceso de observación de la estructura de juego en voleibol. En VIII Congreso Internacional sobre entrenamiento deportivo. Valladolid.

Monge, M.A.(2002). Los complejos básicos y específicos. Apuntes de la maestría de voleibol del INEF de Galicia.

Moreno, A., Moreno, M. P., Julián, J. A. y Del Villar, F. (2005). Estudio de la relación entre la eficacia de las acciones de primer contacto y la eficacia del ataque en voleibol masculino de altonivel. Revisa Kronos, 5, 57-61.

Moreno, M.P.; Molina, J.J. y Santos, J.A. (2008). El saque, sus variables y repercusiones. Clinic Memorial Toño Santos. Granada.

Muchaga, L. F. (2005). Análisis del saque. Curso Internacional de Entrenadores Nivel II. FIVB.

Murphy, P. (1999): Some impressions about the libero player. The Coach, 1, 14-15. FIVB. Lausanne.

Palao, J.M., Santos, J.A. y Ureña, A. (2004). Efecto del tipo y eficacia del saque sobre el bloqueo y el rendimiento del equipo en defensa. RendimientoDeportivo.com, www.RendimientoDeportivo.com/N008/Artic040.htm.
Palao, J.M., Manzanares, P. y Ortega, E. (2009). Techniques used and efficacy of volleyball skills in relation to gender. International Journal of Performance Analysis of Sport, 9, 281-293.

Papadimitriou, K., Pashali, E., Sermaki, I. y Papas, M. (2004). The effect of the opponents' serve on the offensive actions of Greek setters in volleyball games. International Journal of Performance Analysis in Sport, 4,1, 23-33.

Peña, J. (2000). El líbero. La nueva figura del Voleibol de élite contemporáneo. Voleibol Set, 6, 22-24.

Quiroga, M.E.; García Manso, J.M. y Moreno, M.P. (en prensa). Relationship between ingame role and service characteristics of elite women volleyball players.

Selinger, Ay Ackermann, J. (1985). Voleibol de potencia. Buenos Aires. Confederación Argentina de Voleibol.

Toyoda, H.y Herrera, G. (1989). Técnica para entrenadores. Málaga. Unisport.

Ureña, A. e Iglesias, A. (1993). Estudio del rendimiento en recepción en función de la misión posterior. Congreso mundial de ciencias de la actividad física y el deporte. Granada.

Ureña,A.(1998). Incidencia de la función ofensiva sobre el rendimiento de la recepción del saque en voleibol. Tesis Doctoral del Departamento Personalidad, Evaluación y Tratamiento Psicológico. Universidad de Granada.

Ureña, A.; Calvo, R.; Gallardo, C. (2000): Estudio de las variables que afectan al rendimiento dela recepción del saque en Voleibol: Análisis del Equipo Nacional masculino de España. http:// www.efdeportes.com.

Ureña,A.; Santos, J.A.; Martínez, M.; Calvo, R.M.; Oña, A. (2000). La facilitación defensiva a través del saque en el voleibol femenino de alto nivel. European Journal of Human Movement. Motricidad, 6, 175-189.

Ureña, A.; Santos, J.A.; Martínez, M.; Calvo, R.; Hernández, E. y Oña, A. (2001). El principio de variabilidad como factor determinante en la táctica individual del saque en voleibol masculino de nivel internacional. European Journal of Human Movement. Motricidad, 7,63-74.

Ureña, A.; Calvo, R. y Lozano, C. (2002): Estudio de la recepción del saque de voleibol masculino español de élite tras la incorporación del jugador líbero. Revista Internacional de Ciencias de la Actividad Física y el Deporte, 4, 2-11.

Van Der Mars, H. (1989). Observer Reliability: Issues and Procedures. In P. Darst D. \& V. Mancini (eds), Analysing Phisical Education and Sport Instruction ( $2^{\text {nd }}$ ed.), 53-79. Champaign Illinois, Himan Kinectics.

Zimmermann, B. (1995). Principal evolución del voleibol masculino. Internacional Volley Tech. 1/95.

Zimmermann, B. (1999): Changes and potential possibilities with men's world class volleyball. The Coach, 1, 4-12. FIVB. Lausanne.

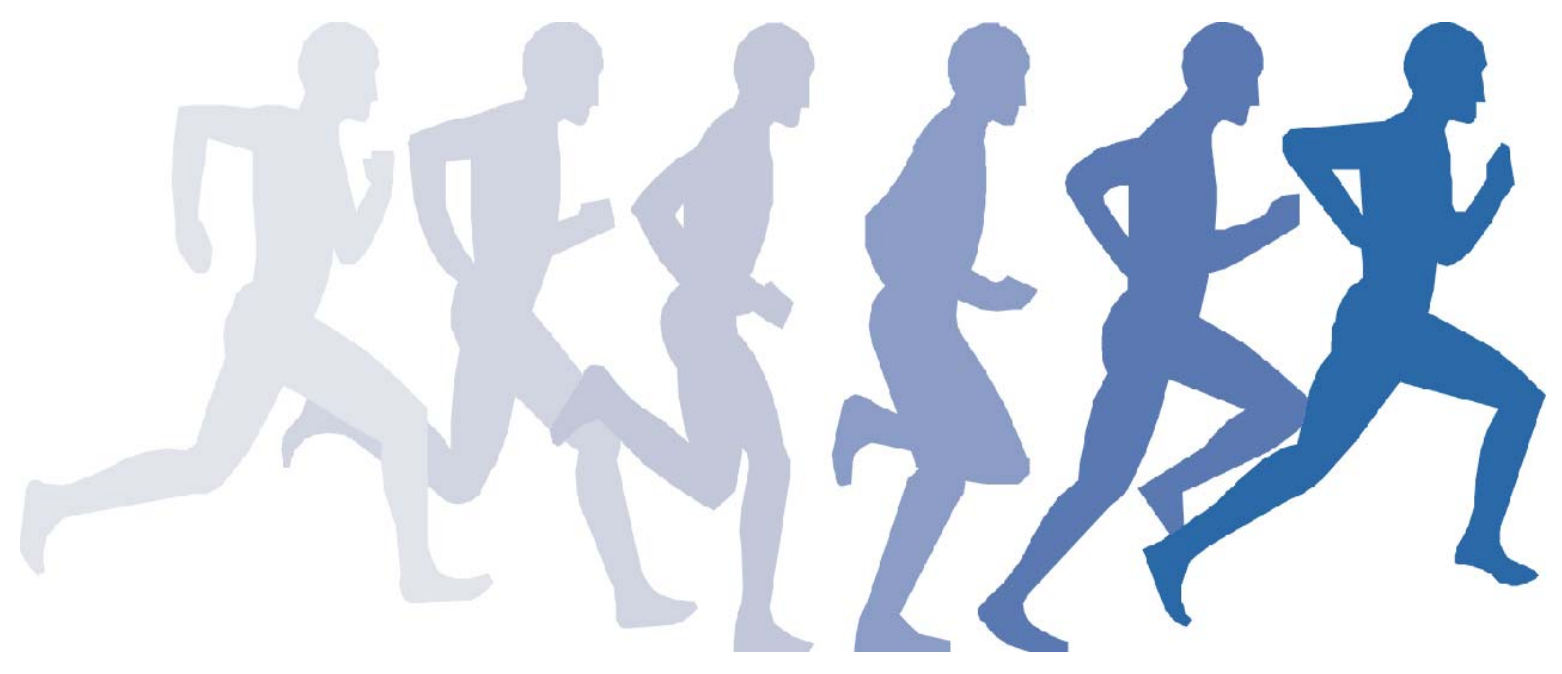

